\title{
LA TESIS JURISPRUDENCIAL 43/1999 "SINDICACIÓN ÚNICA. LAS LEYES O ESTATUTOS QUE LA PREVÉN, VIOLAN LA LIBERTAD SINDICAL CONSAGRADA EN EL ARTÍCULO 123, APARTADO 'B', FRACCIÓN X, CONSTITUCIONAL"
}

\section{INTRODUCCIÓN}

EN EL ESTADO ACTUAL de la evolución del derecho, el cual como sabemos se condiciona por las estructuras económicas y sociales en vigor, el reconocimiento del derecho a la libertad sindical se ha generalizado más entre aquellos países que no han adoptado para su gobierno sistemas catalogados como autoritarios.

Tanto en las modernas Constituciones como en las declaraciones, pactos y convenciones internacionales mediante los cuales se pretende conferir mayor eficacia a los preceptos de aquéllas, se incluye la libertad sindical entre los derechos fundamentales.

Así como no nos es dado concebir ningún tipo de organización social en el cual resulte innecesario el reconocimiento y la protección de derechos como la vida, la libre expresión o manifestación del pensamiento, la intimidad, o la igualdad, tampoco podemos imaginar formas de organización social o modos de estructurar los procesos económicos que tornen innecesaria la existencia de asociaciones de trabajadores o patrones en cuyo beneficio este derecho haya sido reconocido y declarado.

Podemos afirmar que bajo las vigentes condiciones de organización social y económica, resulta indispensable el reconocimiento y la adecuada protección del derecho a la libertad sindical para que el individuo pueda aspirar a vivir conforme a su condición humana.

Entre las características consustanciales a la libertad sindical encontramos:

a) aquellas que se refieren a sus antecedentes primarios, catalogados éstos por un simple elemento de unión de afinidades hacia lo social, económico o productivo; esto es, existe una condición hacia la contin- 
gencia histórica de defensa y reconocimiento de similitudes inherentes a la personalidad humana;

b) el titular o sujeto activo de este derecho lo encontramos en la organización colectiva "de clase", en los trabajadores o patrones que se agrupan en el "sindicato" o "unión" o "asociación", por señalar algunos de los vocablos utilizados en sentido amplio.

c) el señalamiento expreso de "libertad sindical" como ejercicio o manifestación de intenciones que van un paso más adelante del reconocimiento al derecho de asociación; a este respecto basta con examinar algunas disposiciones normativas (y entre ellas está la jurisprudencia que se comenta) en las cuales se reconoce el derecho a la libertad sindical como la serie de elementos tendentes a proteger o amparar los actos que siguen a la manifestación de voluntad de constituir una asociación o a garantizar la acción de ésta, y

d) la ratificación a todo cuanto signifique protección del derecho al libre desenvolvimiento colectivo, o mejor dicho, al derecho constituido en la libre y normada acción de organizaciones conformadas; al derecho de un tipo especial de organización, de asociación, de comunidad de individuos, entendiendo esto como si tal comunidad poseyera un rasgo diferencial respecto de otros derechos fundamentales o sociales.

Consideramos conveniente señalar que en algunos casos se ha utilizado la expresión "libertad sindical" para aludir no a los derechos de las asociaciones de patrones o trabajadores, sino a derechos propios de los integrantes de dichas asociaciones. Esto queda evidenciado con el señalamiento de que la protección del derecho a la libertad sindical, como lo concluiremos, obliga a reconocer algunos derechos "especiales" a todos o a alguno de los individuos integrantes de la organización sindical, como por ejemplo el denominado "fuero sindical" de los dirigentes o representantes. Sin embargo, somos de la opinión que estos derechos no pueden ser confundidos con el derecho a la libertad sindical, ya que lo sirven, lo amparan, lo protegen o lo pueden derivar, pero son diferentes a él en y por su esencia en cuanto al sujeto activo de los mismos.

Con base en lo señalado anteriormente, no queremos dejar de apuntar que la organización colectiva de empleadores o de trabajadores, en tanto agrupación de individuos para la obtención de fines comunes y con algún carácter de permanencia y de organización interna, es una manifestación del ejercicio del derecho de libertad de asociación; por tanto, el hecho 
de que un orden jurídico positivo consagre el derecho a la libertad de asociación obliga a considerar, bajo los supuestos antes dichos, que tales individuos deseen agrupar sus intenciones, intereses, finalidades o aspiraciones profesionales en una agrupación denominada, con tales fines, como un "sindicato", "unión" o "asociación".

Ahora bien, como derivación a este reconocimiento, podremos encontrar la manifestación del derecho a la libertad sindical por lo que ello no hace innecesario que se destinen disposiciones especiales al reconocimiento, interpretación o amparo de este derecho. Y esto es precisamente lo que primordialmente ratifica la jurisprudencia definitiva que se comenta.

\section{ANTECEDENTES RESPECTO A LA LIBERTAD SINDICAL BUROCRÁTICA EN MÉXICO}

Próspero López Cárdenas, citado por Carlos Morales Paulín en su libro Derecho burocrático (publicado por Porrúa en 1995), ha señalado que a principios de este siglo y frente a la organización sindical de los empleados públicos, de los trabajadores de limpia y servicio de agua potable de la ciudad de México, así como de profesores, el Estado buscó desalentar la lucha social de sus empleados a través de la Ley de Pensiones Civiles de Retiro de 1925, así como con el Acuerdo sobre el Servicio Civil de 1934.

En ambos documentos se les garantizaban a tales trabajadores, derechos de naturaleza individual propiciando una táctica sobre la merma de los derechos colectivos.

A pesar de esto, nacieron organizaciones como la Unión General de Trabajadores de Materiales de Guerra (1934), la Alianza de Trabajadores de Salubridad (1935) y la Alianza de Trabajadores del Estado (1935).

Para 1936 la Alianza, convertida en la Federación Nacional de Trabajadores del Estado, convoca a un congreso tendente a fortalecer al movimiento sindical de los empleados públicos, así como pugnar por la inclusión de los burócratas en la Ley Federal del Trabajo. Participaron en este congreso: la Alianza de Telegrafistas Mexicanos; Frente Único de Trabajadores de Caminos; Sociedad Nacional de Empleados Postales; Sindicato Único de Empleados Federales de la SOP; Unión Nacional de Empleados del Gobierno; Unión de Trabajadores de la Secretaría de Re- 
laciones Exteriores; Unión de Empleados y Obreros de la Secretaría de Hacienda; Sindicato Único de Trabajadores de la SEP; Organización de Trabajadores de la Secretaría de Gobernación así como el Frente Único de Trabajadores Oficinistas del Departamento Central.

Frente a lo anterior, el Estado respondió expidiendo en el año de 1938 el Estatuto Jurídico de los Trabajadores al Servicio de los Poderes de la Unión, el cual vino a establecer limitaciones a la libertad sindical, al consignar que en cada dependencia sólo existiría un sindicato, así como limitar la renuncia o separación sindical de los trabajadores e impedir la adhesión a centrales obreras o campesinas.

Con apoyo en la referida normatividad, el Estado organizó a través de la Secretaría de Gobernación, la creación de la Federación de Sindicatos de Trabajadores al Servicio del Estado, la cual se afilió al entonces Partido de la Revolución Mexicana.

Así llegamos hasta la actual Ley Federal de los Trabajadores al Servicio del Estado (publicada en el Diario Oficial de la Federación el 28 de diciembre de 1963), en donde coexisten artículos como el 68,69, 78, que ratifican el ánimo de control del órgano público sobre sus empleados. Transcribimos a continuación estos artículos:

Artículo 68. En cada dependencia sólo habrá un sindicato. En caso de que concurran varios grupos de trabajadores que pretendan ese derecho, el Tribunal Federal de Conciliación y Arbitraje otorgará el reconocimiento al mayoritario.

Artículo 69. Todos los trabajadores tienen derecho a formar parte del sindicato correspondiente, pero una vez que soliciten y obtengan su ingreso, no podrán dejar de formar parte de él, salvo que fueren expulsados.

Artículo 78. Los sindicatos podrán adherirse a la Federación de Sindicatos de Trabajadores al Servicio del Estado, única central reconocida por el Estado.

\section{LA TESIS JURISPRUDENCIAL 43/1999}

Con fecha 27 de mayo del presente año, el pleno de la Suprema Corte de Justicia de la Nación aprobó la tesis jurisprudencial que se comenta.

El sentido de ésta consiste en ratificar que nuestra Constitución consagra, respecto a la libertad sindical, un elemento "pleno de universalidad, partiendo del derecho personal de cada trabajador a asociarse y reconociendo un derecho colectivo, una vez que el sindicato adquiere existencia y personalidad propias". 
Con base en lo anterior y atendiendo al control constitucional que le compete a la Suprema Corte de Justicia de la Nación, la misma declaró que aquellas leyes o estatutos que prevén la sindicación única, violan la libertad sindical consagrada en el artículo 123, apartado "B", fracción $\mathrm{X}$, constitucional.

En consecuencia, esta declaración de inconstitucionalidad se aplicará a aquellas leyes o estatutos de dependencias burocráticas de carácter federal, estatal o municipal como a las normas que al respecto regulan a los diferentes regímenes jurídicos del trabajo burocrático. Entre estos encontramos: el propio régimen burocrático especial para cada entidad federativa, así como el régimen especial para cada municipio; el régimen jurídico burocrático típico; el régimen jurídico especial para el personal del servicio exterior; el régimen especial para el servicio electoral y el régimen burocrático especial para los empleados del Poder Judicial de la Federación, entre otros.

La declaración de inconstitucionalidad, atendiendo a los considerandos de las resoluciones que tuvieron de base para conformar la tesis jurisprudencial, refiere a ciertas circunstancias de derecho:

a) Que se ratifica el derecho de libertad sindical, en términos de lo establecido por el artículo 123 constitucional tanto en su apartado "A" como en el "B".

b) Que con anterioridad a esta libertad sindical existe un derecho de asociación.

c) Que para llegar a los ámbitos de universalidad, a que se refiere la tesis respecto a la libertad sindical, se parte primero de un derecho personal del trabajador (nunca habla del patrón) a asociarse.

d) Que se dan las pautas de reconocimiento del ejercicio de un derecho colectivo.

e) Que también con anterioridad al principio de libertad sindical además del reconocimiento de una garantía o derecho de asociación, debió "constituirse" un sindicato.

f) Que la sindicación única restringe el derecho de libertad sindical.

$\mathrm{Al}$ atender los términos en que se redacta y constituye la tesis jurisprudencial que se comenta, hacemos notar los puntos que anteceden. Sin embargo, si nos sometiéramos al examen gramatical de la tesis, nuestro inciso f) sería redactado bajo otros parámetros. 
En efecto, no compartimos el sentido en la redacción de la parte final de la tesis cuando determina: "toda vez que al regular la sindicación única restringe la libertad de asociación de los trabajadores para la defensa de sus intereses."

Consideramos que existe un error de incongruencia gramatical en la redacción de la tesis en cuanto que, como ya hemos señalado, un primer paso al hablar del tema que nos ocupa es precisar los contenidos de dos tipos de derechos o garantías, una primera denominada "de asociación" y una segunda de "libertad sindical"; esto es, ratificamos que antes de que existan los contenidos regulatorios de una libertad sindical, debieron haberse reconocido los derechos o garantías de asociación. Por tanto, la redacción debió haber indicado que "al regular la sindicación única se restringe la libertad sindical", y no como se señala que "la sindicación única restringe la libertad de asociación".

Por otro lado, resulta conveniente señalar que ya desde hace algunos años, algunos doctrinarios como el maestro Mario de la Cueva, manifestaron su desacuerdo respecto al contenido de los artículos 68, 69 y 78 de la Ley Federal de los Trabajadores al Servicio del Estado ya antes precisados.

Ya señalaba el maestro de la Cueva que tales artículos resultaban inconstitucionales entre otros argumentos porque "constituyen una violación grave a las libertades humanas, en el mundo democrático no parece posible que los hombres, que pueden cambiar de nacionalidad no puedan dejar de pertenecer a un sindicato; parece algo semejante a la hipótesis de un matrimonio indisoluble" (Nuevo derecho mexicano del trabajo, 17a. ed., México, Porrúa, 1978, p. 634).

Con relación a otro punto específico sobre libertad sindical, es importante tener presente que México ratificó en 1950 el Convenio 87 de la Organización Internacional del Trabajo (OIT). Este Convenio, relativo a la libertad sindical y a la protección al derecho sindical, fue adoptado con fecha 9 de julio de 1948 por la XXXI Conferencia Internacional del Trabajo en San Francisco, California, y publicado en nuestro país en el Diario Oficial de la Federación el 10 de octubre de 1950.

Con base en este convenio podemos precisar tres puntos:

a) Que hoy día la Suprema Corte de Justicia de la Nación declara que las leyes o estatutos que prevén la sindicación única violan la libertad 
sindical consagrada tanto en el artículo 123 constitucional como en el contenido de este Convenio 87;

b) Que los principios de libertad sindical precisados párrafos arriba, a efecto de que se apliquen o no a los trabajadores que laboran bajo el régimen burocrático especial de militares, marinos, agentes del Ministerio Público o miembros de las instituciones policiales, deberán estar lo suficientemente bien justificados en las normas que regulan, en términos de la fracción XIII del apartado "B" de artículo 123 constitucional, el trabajo de tales servidores públicos.

Determinamos esto por el contenido del artículo 9o. punto 1o. del Convenio 87, que a la letra dice: "La legislación nacional deberá determinar hasta qué punto se aplicarán a las fuerzas armadas y a la policía las garantías previstas por el presente Convenio."

c) Que en consecuencia, los restantes servidores públicos gozarán de idénticas libertades sindicales a las disfrutadas por los trabajadores que se rigen bajo el apartado "A" del artículo 123 constitucional.

\section{A MANERA DE CONCLUSIÓN}

Desde nuestra perspectiva, razonada e importante ha sido la tesis jurisprudencial dictada por el pleno de nuestra Suprema Corte de Justicia de la Nación, ya sea desde la perspectiva material en cuanto al control constitucional jurisdiccional que le compete, como formalmente por la ratificación del derecho y garantía de la libertad sindical; a pesar de esto, también es cierto que no podemos dejar de lado las consideración históricas que llevaron al Estado mexicano, o mejor dicho, a su gobierno, a controlar la sindicalización burocrática. El coorporativismo de este elemento de voluntad de asociación, más político que de representación sindical, será un punto a considerar al momento de reglamentar y adecuar las disposiciones legislativas con la resolución jurisprudencial que se comenta. Este es un factor político preocupante.

Por último, para la plena vigencia y adecuada protección del derecho a la libertad sindical, es preciso reconocer e instituir medios de protección, tanto en el área nacional como en el ámbito internacional. Se ha precisado que éstos deben ser:

a) El derecho individual que participa hacia una libre constitución de asociaciones profesionales como a la libre afiliación a las mismas. Estos 
derechos son modos de ejercicio del derecho individual a la libertad de asociación.

b) El derecho de las organizaciones profesionales a autogobernarse, actuar y subsistir con libertad, el cual se desdobla en una serie de derechos perfectamente individualizables. Se dice que este conjunto de derechos está constituido por la "libertad sindical", en sentido estricto.

c) El derecho a una especial protección que ha de ser reconocida a los dirigentes sindicales, llamado generalmente "fuero sindical".

d) Los derechos que deben ser individualmente reconocidos a los integrantes de las organizaciones profesionales frente a las propias organizaciones que ellos integran.

Consideramos que hacia estos rumbos deberán de dirigirse los esfuerzos del vigente y actual derecho a la libertad sindical.

Juan José Ríos ESTAVILLO 